\title{
Carbon Dioxide Is Not the Chief Culprit of Global Warming
}

\author{
Xinxing Yang \\ The Research Center of Climate Change and Impact, Chinese Research Academy of Environmental Sciences, Beijing, China
}

Email address:

yangxinxing0343@126.com, yangxinxing0343@163.com

\section{To cite this article:}

Xinxing Yang. Carbon Dioxide Is Not the Chief Culprit of Global Warming. International Journal of Environmental Protection and Policy. Vol. 7, No. 4, 2019, pp. 99-108. doi: 10.11648/j.ijepp.20190704.11

Received: June 26, 2019; Accepted: August 6, 2019; Published: August 26, 2019

\begin{abstract}
So far, the climate on the Earth, from beginning to end, has been changing, making in circle and not stopping. About this point, the specialists seemly have no disagreement. However, About causes of climate change, they indeed have divergence, and as for whether carbon dioxide is or not main cause of global climate warming, their divergence is much more large. Some specialists considered that natural factors are main causes led to climate change, and influence of anthropological factors on climate change is very very small. However, the other specialists considered that anthropological factors are important cause led to climate change, and also emission of greenhouse gases is main causes led to climate warming and at which, emission of carbon dioxide is the most main cause led to global climate warming. Still also some specialists consisted that carbon dioxide emitted by human activities is a chief culprit led to global warming. The Intergovernmental Panel on Climate Change (IPCC) stated that the climate on the Earth is warming. Emission of greenhouse gases led to climate warming, and carbon dioxide is main cause led to climate warming, and especially the carbon dioxide emitted by human activities is the most main cause led to global warming. Now, the climate on the earth is getting more and more warming. If the people did not control emission of carbon dioxide, the global climate warming would bring ecological cataclysm to the mankind. The climate change theory described by IPCC is called "Global warming" theory, or "Greenhouse effect" theory. The global warming theory, or greenhouse effect theory, has had very large influence on the all over the world. In China, also there are a lot of people who believe that "global warming" is true, is right and is scientific. Especially in Chinese academic circles, there are many specialists who especially believe "global warming", and they forcefully trumpeted that the global climate is getting more and more warming. The carbon dioxide was considered as a chief culprit resulted led to global warming. Still also there are some people who placed "global warming" theory on the god altar, and accepted some people to prostrate themselves in worship. The "Global warming" theory put forward by IPCC, at home and abroad, all has received a lot of serious criticism. According to basic theory of classical physics and basic fact of climate observation, we can prove that emission of greenhouse gases is not main cause led to climate change, and also carbon dioxide is not most main cause led to climate warming, and still also carbon dioxide emitted by human activities was not a chief culprit led to global warming. Thus, large decrease of emission of carbon dioxide cannot control the greenhouse effect, and also cannot prevent climate warming, and still also cannot stop happening of climate cataclysm.
\end{abstract}

Keywords: Carbon Dioxide, Source, Sink, Global Warming, Greenhouse Effect, Greenhouse Gases

\section{Introduction}

So far, the climate on the Earth, from beginning to end, has been changing, making in circle and not stopping. About this point, the specialists seemly have no disagreement. However, About causes of climate change, they indeed have divergence, and as for whether carbon dioxide $\left(\mathrm{CO}_{2}\right)$ is or not main cause of global climate warming, their divergence is more large.

Some specialists considered that natural factors are main causes led to climate change, and influence of anthropological factors on climate change is very very small. However, the other specialists considered that anthropological factors are important cause led to climate change, and also emission of greenhouse gases is main causes led to climate warming and at which, emission of $\mathrm{CO}_{2}$ is the most main cause led to global climate warming. Still also some specialists consisted that $\mathrm{CO}_{2}$ emitted by human activities is a chief culprit led to global warming.

The assessment report of climate change provided by the IPCC (Intergovernmental Panel on Climate Change) stated 
that. [1-6]

The climate on the Earth is warming. Emission of greenhouse gases led to climate warming, and $\mathrm{CO}_{2}$ is the main cause led to climate warming, and especially the $\mathrm{CO}_{2}$ emitted by human activities is the most main cause led to global warming. If the people did not control emission of carbon dioxide, then the climate on the earth would be more and more warming. The global warming would bring ecological cataclysm to the mankind.

The global warming theory put forward by IPCC has had very large influence on the all over the world. In China, also there are a lot of people who believe that "global warming" is true, is right and is scientific. Especially in Chinese academic circles, there are many specialists who especially believe "global warming". They forcefully trumpeted global warming theory. The carbon dioxide is said to be the chief culprit led to global warming. Still also they placed "global warming" theory on the god altar, and accepted some people to prostrate themselves in worship. [7-9]

However, the "Global warming" theory, at home and abroad, has met a lot of serious criticism. [10-16]

Prof. Habibula Abudusaev, the Head of Cosmos Research Department, Pulkevo Astronomical Observatory, Russia Science Academy, considered that. [17]

Main cause of climate change is the Solar activities, and the influences of human activities on the climate change is very very small. Present "greenhouse effect" theory, on the appearance, seems to be reasonable, and however, really, that is short of conclusively scientific evidence.

Prof. Wanshanmaode, Tokyo Industry University, Japan, stated that [18] carbon dioxide is not the chief culprit of climate warming. Carbon dioxide and climate warming are tow different problems. Indeed, in the last 100 years, the air temperature on the Earth appeared a trend of rise. But, rise of the temperature only is $0.5^{\circ} \mathrm{C}$, and on the global history, which is not abnormal. In the 1940-1980 years, a lot of fossil fuel were burnt, at which the air temperature not only did not increase, but also decreased. The so called "carbon dioxide is the chief culprit of climate warming" has no scientific evidence.

Prof. S. Fred Singer, Virginia University, and Mr. Danis T. Ivory, the lifelong researcher of Hardeson Institute, US, in their book:"Unstoppable Global Warming: Every 1500 years", stated that. [19]

The "Greenhouse effect" theory is not all-powerful, and really, in which there are some areas they cannot offer an acceptable explanation. First, evidently, change of carbon dioxide cannot explain the climate change happened on the Earth that we have known, including Roman warming period, the cold period of European Middle Ages, the warming period of the Middle Ages, and small ice period. Second, "greenhouse effect" also cannot explain recent change of the air temperature.

Prof. Wang, Mingxing the Atmospheric Institute of Chinese Academy of Sciences, when accepted the interview of the reporter of "Chinese Science News Paper, said that [20].

Whether "greenhouse effect" is or not main cause of climate warming? Especially, on the problem of influence of carbon dioxide that now some people extremely hanker on climate, so far, it has not been seen that there are enough evidences that could persuade the people to believe that the conclusion is unique, and is tight, is scientific.

Prof. Ding, Zhongli, the former vice director of China Academy of Sciences and the Academician of Chinese Engineering Academy, said that [21] the power of carbon dioxide emitted by human activities resulted in global warming is very small, and which is not enough to change natural law of the climate change......., climate change is a progress of wave motion,......, the work of replying or research of climate change should go back to the rational orbit........ climate warming not only has been a scientific problem, but also has extended to the areas of politics, economy, diplomacy, and even the area of the religions. Now, climate change problem is placed on the god altar by some people, and to accept the some people to prostrate themselves in worship.

Prof. Jiang, Xiaoyuan, Shanghai Communication University, in his paper stated that [22] carbon emission has become a extremely large politic problem on all over the world, so there is so called "carbon politics". Carbon politics is newly political play. In this play, potentially and also evidently profited persons belong to the new energy sources groups in world.

The harm of global warming and necessity of environment protection advocated by IPCC, in the world there is certain market, and in China, also there is very large influence, however not to forget, also a lot of people considered that so called "global warming" was one monstrous lie, one fraud, one plot.

A paper of English journal Nature stated that the sceptic of global warming considered that the global warming, was a farce, and even considered that "global warming" was a tool, or a means made by some bad scientists to cheat the Governments and public. One France scientist said that "global warming" is a false proposition. [23]

Nearly soon after IPCC published the first scientific assessment report of climate change, some scientists who doubt climate warming, blow for blow, set up one organization that was called the Non-Intergovernmental Panel on Climate Change (NIPCC) in 1993, which was led by Doc. F. Seitz, the lifelong Professor and the former chairman of American National Academy of Sciences, who collected signatures of 31478 persons, among whom there are 9029 persons who were doctors and 5819 persons were physicist and scientists in the space science sphere.

NIPCC gave, item by item, sharp criticisms to the scientific assessment report of Climate change of IPCC, and in public issued a statement that appeals the American government do not support KYOTO PROTOCOL TO THE UNITED NATIONS FRAMEWORK CONVENTION ON CLIMATE CHANGE and similar agreements. Limit of emission of greenhouse gases is harmful to the environment and are harm to the basic benefit of all human kind.

It is noticed that, at home and abroad, the most of the supporters of climate warming theory, almost all are the government officers and the scholars who are employed by the Governments. Especially, it is worth noticing that the largest trumpeter of climate warming theory on the world now is Mr. 
Abert Gore (1948 - ), a former vice president of USA. However, the specialists of the academic circles and the professors in the universities, and all considered that the climate warming theory is not worth a glance.

Mr. Trump, the president of USA, during the period running for the presidency, many times stated that the concepts of "climate change", "global warming", etc, are the frauds made by some persons, and which would seriously influence work and living of the workers of mining industry, USA. He claimed that USA would withdraw from Paris Agreement, and stop sustaining all fund of USA for the climate change projects of UN.

March 28, 2017, President Trump signed a administrative order that canceled a series of the bills that the Obama's Government issued to control climate change.

According to basic theory of classical physics and basic fact of climate change, we can prove that emission of greenhouse gases is not main cause led to climate change, and also carbon dioxide ( $\left.\mathrm{CO}_{2}\right)$ is not most main cause led to climate warming, and still also $\mathrm{CO}_{2}$ emitted by human activities was not a chief culprit led to global warming.

Thus, large decrease of emission of carbon dioxide cannot control the greenhouse effect, and also cannot prevent climate warming, and still also cannot stop happening of climate cataclysm.

On the grand scale decreasing emission of carbon dioxide would exhaust the people power and drain the treasury of the Governments, and also which would impact on normal development of the national economy.

We would like to suggest that the Governments all over the world do not easily believe so called "global warming", and also do not attend and support the international activities of global climate warming problem.

\section{Structure of Circle Layers of the Earth and Carbon Dioxide [23]}

The science research stated that all celestial bodies (star) that are spherical, all have the structure of circle layers. The earth also has complex structure of circle layers. The earth mainly has four basic structures of circle layers, which are respectively: (1) The atmospheric sphere; (2) The water sphere; (3) Biosphere; and (4) Geo sphere.

The substances of circle layers of the earth all contain a lot carbon, and they would transform into carbon dioxide. So geo - sphere is a importantly coming source of carbon dioxide of the atmosphere.

Table 1. Carbon dioxide in the circle layers in the natural world.

\begin{tabular}{ll}
\hline Circle layer of the earth & Content of, $\mathrm{CO}_{2} \mathbf{t}$. \\
\hline Atmosphere sphere & 2300 billion \\
Water sphere & 130000 billion \\
Biosphere & 500 billion \\
Geological sphere & 0.24 billion billion \\
Photo synthesis & 1600 billion \\
\hline
\end{tabular}

Source: [23] p. 75.

\subsection{Geological Sphere and Carbon Dioxide}

\subsubsection{Concept of the Geological Sphere}

The people generally separated the earth body (solid parts) into three parts, they are respectively: (1) the earth's crust, (2) the earth's mantle, and (3) the earth's core. The earth's crust indicated a hard crust of the earth's out layer, which is one part between the earth surface to Mohor face, and average thick is about $30 \mathrm{~km}$, most large thick is about $65 \mathrm{~km}$.

\subsubsection{Carbon Dioxide of Geological Sphere}

A lot of rocks contain carbon, like lime, calcite, marble, dolomite, etc. While content of carbon dioxide of the Magmatic rock is about $0.43 \%$, and content of carbon dioxide of Neutral rock is about $0.57 \%$, and content of carbon dioxide of Acidic rock is about $0.32 \%$, in the gases separated, carbon dioxide is amount for 93.2.

\subsection{Atmosphere Sphere and Carbon Dioxide}

\subsubsection{Concept of the Atmosphere Sphere}

According to the difference of the temperature, pressure, density, component, and ionization, etc., the atmospheric layer could be classified to five layers, which are respectively: (1) Troposphere; (2) Stratosphere; (3) Mesosphere; (4) Thermosphere, and (5) Escape layer.

In addition, also there are so called: (1) Boundary layer; (2) Inversion layer; (2) Ionosphere; (3) mixing layer, etc.

Atmospheric sphere is a circle layer of most outside of the earth. Main component of which are respectively: Nitrogen $\left(\mathrm{N}_{2}\right)$, Oxygen $\left(\mathrm{O}_{2}\right)$, Hydrogen $(\mathrm{Ar})$ and Carbon dioxide $\left(\mathrm{CO}_{2}\right)$ and water vapor and so on, in which $\mathrm{N}_{2}$, $\mathrm{O}_{2}$ and $\mathrm{Ar}$ are called quasi-stationary components, and $\mathrm{CO}_{2}$ is called changeable component.

The atmospheric sphere or atmospheric layer is thick layer of gases: The air density of the atmospheric layer is decreased by height, and while the air layer is higher, the air is thinner, and it is estimated that the mass of the atmosphere is about 6000 billion t., and nearly one millionth of total mass of the earth.

In the recent, quite a few ten years, the people start to care extremely for change of concentration of the atmosphere, and this is because except that they would influences cycle of the matter in the natural world, also influence living and development of the mankind and the other living things.

\subsubsection{Carbon Dioxide of the Atmosphere Sphere}

Carbon dioxide is a very important component of the atmosphere. On the volume, or quantity, content of carbon dioxide in the atmosphere is about $0.03 \%$, or $0.04 \%$, and the concentration is about $385 \mathrm{mg} / \mathrm{kg}$. Total amount of carbon dioxide in the atmosphere is about 2350.0 billion $\mathrm{t}$. and carbon dioxide used by photosynthesis of plants is about 700 billion each year.

The research result stated that before industrial revolution, concentration of $\mathrm{CO}_{2}$ in the atmosphere is about is 280 
$\mathrm{mg} / \mathrm{kg}$. However, after industry revolution (about 1760), due to emission of combustion of a lot of fossil fuel, the concentration of carbon dioxide in the atmosphere, is more and more high. For example, in the $1850,295 \mathrm{mg} / \mathrm{kg}$; and in the $1958,313 \mathrm{mg} / \mathrm{kg}$; in the $1971,323 \mathrm{mg} / \mathrm{kg}$; in the 1976,332 $\mathrm{mg} / \mathrm{kg}$; in the $2000,350 \mathrm{mg} / \mathrm{kg}$; in the $2010,390 \mathrm{mg} / \mathrm{kg}$. Now, possibly it is higher than $400 \mathrm{mg} / \mathrm{kg}$. Now, it is increasing continually with speed of $1.5 \mathrm{mg} / \mathrm{kg}$ every year.

\subsection{The Water Sphere and Carbon Dioxide [23]}

\subsubsection{Concept of Water Sphere of the Earth}

The water sphere indicated different water bodies in the world, including water bodies of rivers and streams, lakes, ocean, and water underground, and water of the atmosphere, and water in organism body, etc. On the earth, there are about 0.14 million $\mathrm{km}^{3}$ of water, at which seawater is account about for $97.2 \%$, and water on the land is account about for $2 \%$.

\subsubsection{Carbon Dioxide in Water Sphere}

There are 130000 billion $t$. of carbon dioxide in the water sphere. which is 60 time more than that of atmosphere. Carbon dioxide from the ocean to the atmosphere is about 15.0 billion $t$. and carbon dioxide absorbed from the atmosphere is about 20.0 billion $t$. each year. Net increase of carbon dioxide in the atmosphere is about 50.0 billion $\mathrm{t}$. every year.

\subsection{Biosphere and Carbon Dioxide [23]}

\subsubsection{Concept of Biosphere of the Earth}

A space of thin layer surrounding the earth is called biosphere, or organism circle, where that is a place of meeting of water, air and land, and where all animal and plants, and microorganisms live together, and where 90 of living maters in the natural world all converge. It is estimated that the quality of biosphere is about 1800 billion $t$.

\subsubsection{Carbon Dioxide of Biosphere}

The bodies of animal and plants, contain fat, protein and starch, etc., which all are compound of carbon. Global green plants in the world from the atmosphere absorbed 150 billion t. of carbon, that is, 550 billion t. of carbon dioxide each year. The total amount of carbon that all the green plants on the land contained, is about 650 billion t. The total amount of carbon that organisms in the ocean contented is about 66.9 billion $t$. The carbon dioxide in the atmosphere, one part of which enter the ocean, the other are absorbed by green plants. by photo synthesis formed organic substance. After the remains of the animals and plants are decomposed by microorganisms, they also would release carbon dioxide.

\section{Concept of Sources and Sink}

\subsection{Emission Source of Environmental Pollutants}

In the research field of environmental sciences, the pollution source, or simply is called source, mainly indicated a places, or a fields, a equipment, or an installment, etc., where the pollutants of the environment were produced and emitted out. For example, a boiler or a stove, or a furnace, which could burn the coal, or firewood, or oil, or natural gas, etc., and produce and emit the pollutants to the environment, all are called emitted source of the pollutant, or source of pollutants.

According to need of research work, the pollution source was separated two kinds, which are respectively: (1) Natural source, and (2) Anthropological source.

\subsubsection{Natural Source}

Natural Source indicated that in the natural world, there are the places, or the fields, etc., which could emit pollutants to the environment. For example, forest fire produced by natural factors, volcano eruption, etc.

\subsubsection{Anthropological Source}

Anthropological Source indicated the pollution source formed by human activities. For example, the a boiler or a stove, or a furnace, and cars, planes trains burned fossil fuel, etc.

Anthropological Source still could be separated into: (1) Industrial pollution source, (2) Agricultural pollution source, (3) Life pollution source, and (4) Traffic pollution source, etc.

According to kinds of pollutants, pollution sources still also could be separated into: (1) Pollution source of organic substance, (2) Inorganic substance, (3) Heat pollution source, (4) Noise pollution source, (5) Pollution source of electro-magnet wave, (6) Pollution source of radioactive substance, (7) Photo pollution source, etc.

\subsection{Sink of Environmental Pollutants}

In the research field of environmental sciences, the sink of pollutants, or simply is called the sink, mainly indicated a plant, a tree and a place, or a field, or a equipment, or an installment, etc., where the pollutants of the environment would be absorbed, and converge, or where they would be transformed into the other substance finally, which could be toxic, or is not toxic. For example, a green tree could absorb carbon dioxide from the atmosphere, and transform it into organic substance by photosynthesis, and then this tree is a sink of the carbon dioxide.

In the natural world, the green plants and the ocean are two most important sinks of carbon dioxide of the atmosphere. It is estimated that there are about 500.0 billion t. of carbon dioxide from the atmosphere every year that were absorbed by green plants, and by photosynthesis formed the organic substance.

In addition, still there are about 20.0 billion $t$. of carbon dioxide from the atmosphere every year that entered the ocean, and converged, or kept in the ocean, or transformed into the other organic substance.

\section{Sources of Carbon Dioxide in the Atmosphere [23]}

Total emission of carbon is about 68.0 billion t., in the world each year, that is about 249.4 billion $t$. 


\subsection{Natural Sources of Carbon Dioxide}

In the natural world, the carbon dioxide emitted to the atmosphere is about 1.789 billion t. every year. Natural emission sources of carbon dioxide in the Atmosphere include:

1) The Carbon Dioxide emitted by animals.

2) The Carbon Dioxide emitted by plants.

3) The Carbon Dioxide emitted by microorganism in soil.

4) The Carbon Dioxide released by ocean to atmosphere.

5) The Carbon Dioxide emitted by Forest Fire produced by natural factors.

6) The Carbon Dioxide emitted by volcanoes eruption.

7) The Carbon Dioxide emitted by activities of hot spring.

8) The Carbon Dioxide emitted by Rock Weathering.

\subsubsection{The Carbon Dioxide Emitted by Animals}

The emission of breath process of animals also is one of the important emitted sources of carbon dioxide. Carbon dioxide emitted by breath of each animal every day is about $0.4 \mathrm{~kg}$. Carbon dioxide emitted by the animals is about a few billion t. Carbon dioxide emitted by breath of livestock is about 8.769 billion t. each year in the world. [23] pp. 85; 88

\subsubsection{The Carbon Dioxide Emitted by Plants}

The green plant could compose organic substance by photosynthesis at days, and would release $\mathrm{CO}_{2}$ by breath process at nights. The $\mathrm{CO}_{2}$ emitted by Taiga forest, or Boreal forest (Northern forest) is about 249.5 billion $t$. each year in the world. The $\mathrm{CO}_{2}$ not used and keeping in the atmosphere by destruction of vegetation is about 77.01 billion t each year in the world. [23] pp. 83; 88-89

\subsubsection{The Carbon Dioxide Released by Microorganism in Soil}

Breath process of the microorganisms in the soil is one of the important sources of carbon dioxide in the atmosphere. The carbon dioxide emitted by breath process of microorganisms in the soil, is about 68.15 billion $t$. of carbon, that is, 249.4 billion $t$. of carbon dioxide. [23] p. 83.

\subsubsection{The Carbon Dioxide Released by Ocean to Atmosphere}

The sea or ocean is a large barn of the carbon, which has stored $1.3 \times 10^{14} \mathrm{t}$, of carbon dioxide. Carbon dioxide in the sea water is very much, which is 60 times that of the atmosphere. The carbon dioxide from the ocean to atmosphere is about 15.4 billion $t$. th the world every year. [23] pp. 8694.

\subsubsection{The Carbon Dioxide Emitted by Forest Fire Produced by Natural Factors}

As everybody knows, forest fire on the earth, not only could destroy property and lives of the people, but also could emitted carbon dioxide to the atmosphere. Forest fire is much to much fearful to us humans It is estimated that the land of forest of every hectare can store $\mathrm{CO}_{2}$ of 50-80 tones. Result of research by Mr. Mark Adams, Sydney University, Australia, stated that in the Australia, carbon dioxide emitted by forest fires is about 0.105 billion tones every year.

\subsubsection{The Carbon Dioxide Emitted by Volcanoes Eruption [23]}

Volcanoes on the earth erupted large amount of carbon dioxide every year. There are 1000 the recent volcanoes, and 523 living volcanoes in the world, in which there are 455 on the land, and still 68 at the bottom of the sea. Each year, they emitted 0.03 billion $t$. of carbon, that is, 0.1100 billion $t$. of carbon dioxide to the atmosphere.

In the 1815, 4-7 month, while the Tabola Volcano was erupting, the erupted substance had about $1517 \mathrm{~km}^{3}$.

\subsubsection{The Carbon Dioxide Emitted by Activities of Hot Spring [23]}

In the world there are a lot of hot springs, especially carbonate hot springs, they from the inside of the earth, bring carbon dioxide to the earth surface, and incoming into the atmosphere.

\subsubsection{The Carbon Dioxide Emitted by Rock Weathering [23]}

In the earth's crust, there are limestone, marble, dolomite, and other minerals, etc., which contained a lot of carbon. If the calcium carbonate and magnesium carbonate in these mineral were decomposed, and released carbon dioxide out, then carbon dioxide in the atmosphere would increase more than 25000 times than at present.

\subsection{Anthropological Emission Sources of Carbon Dioxide [23]}

Anthropological emission sources of $\mathrm{CO}_{2}$ of the atmosphere could be separated as follows:

1) The Carbon Dioxide Emitted Emission of $\mathrm{CO}_{2}$ by Combustion of Fossil Fuel.

2) The Carbon Dioxide Emitted by Combustion of Firewood.

3) The Carbon Dioxide Emitted by combustion of straw of agricultural crops.

4) The Carbon Dioxide increased by cutting down forest.

5) The Carbon Dioxide Emitted by forest fire resulted in by human activities.

6) The Carbon Dioxide Emitted by Industrial Production processes.

7) The Carbon Dioxide Emitted by breath of humans.

8) The Carbon Dioxide Emitted by smokers.

Carbon increased in the atmosphere by anthropological activities, including emission of burning coal, oil, and natural gases, etc., is about 7.0 billion $t$., that is about 25.67 billion $t$. of carbon dioxide, in the world each year. [23]

\subsubsection{The Carbon Dioxide Emitted by Combustion of Fossil Fuel [23] p. 88}

Coal, oil and natural gases, etc., are called fossil fuel. In the past more than 100 years, consumed quantity of fossil fuel early increased 30 times. The $\mathrm{CO}_{2}$ emitted by human activities mainly is from burning process of fossil fuel. Carbon dioxide emitted by combustion of fossil fuel is about 
10.0 billion $t$. in the world, each year. [23] Their formulas of chemical reaction respectively are:

The $\mathrm{CO}_{2}$ emitted by coal burning is:

$$
\mathrm{C}+\mathrm{O}_{2}=\mathrm{CO}_{2}
$$

The $\mathrm{CO}_{2}$ emitted by oil burning is:

$$
\mathrm{C}_{\mathrm{X}} \mathrm{H}_{\mathrm{Y}}+(\mathrm{x}+\mathrm{y} / 4) \mathrm{O}_{2}=\mathrm{xCO}_{2}+\mathrm{y} / 2 \times \mathrm{H}_{2} \mathrm{O}
$$

The $\mathrm{CO}_{2}$ emitted by natural gas burning is:

$$
\mathrm{CH}_{4}+2 \mathrm{O}_{2}=\mathrm{CO}_{2}+2 \mathrm{H}_{2} \mathrm{O}
$$

\subsubsection{The Carbon Dioxide Emitted by Combustion of Firewood [23] p. 88}

Since ancient time, Chinese farmers nearly all used firewood as fuel to boil food, and to heat the room in cold winter. Emission of carbon dioxide is very large in China. Firewood used as fuel all are organic substance, and which could burn in air and form $\mathrm{CO}_{2}$ and $\mathrm{H}_{2} \mathrm{O}$ :

$$
\mathrm{C}_{\mathrm{X}}\left(\mathrm{H}_{2} \mathrm{O}\right)_{\mathrm{Y}}+\mathrm{xO}_{2}=\mathrm{xCO}_{2}+\mathrm{yH}_{2} \mathrm{O}
$$

\subsubsection{The Carbon Dioxide Emitted by Combustion of Straw of Agricultural Crops}

The farmers in China have accused burning straw of agricultural crops in the crop fields in Autumn every year, and by which the amount of carbon dioxide emission emitted is very large.

\subsubsection{The Carbon Dioxide Increased by Cutting down Forest [23]}

Now, the tropical rain forests are disappearing with average speed of 245-900 hectares, in the world every year. Combustion of forest wood would emit a lot of carbon dioxide, and carbon dioxide absorbed by forest wood decrease much largely, and also which changed the original sink of carbon dioxide of forests to source of carbon dioxide of the atmosphere.

\subsubsection{The Carbon Dioxide Emitted by Forest Fire Resulted in by Human Activities [23]}

There are many forest fires that are burned by anthropological factors.

The amount of carbon dioxide emitted by anthropological frost fires is very large.

\subsubsection{The Carbon Dioxide Emitted by Industrial Production Processes [23]}

In the industrial production process, like that of cement, lime, chemical industry, etc., there are a lot of carbon dioxide was emitted out, the carbon dioxide emitted by Industrial Production activities is about 3.667 billion $t$. in the world each year. For example, in the production process of $\mathrm{CaO}$, at the condition of high temperature, $\mathrm{CaCO}_{3}$ is decomposed into $\mathrm{CaO}$ and $\mathrm{CO}_{2}$ :

$$
\mathrm{CaCO}_{3}=\mathrm{CaO}+\mathrm{CO}_{2}
$$

\subsubsection{The Carbon Dioxide Emitted by Breath of Humans [23]}

Human for living, need breathing. One person need inhale oxygen of $0.75 \mathrm{~kg}$, and emit carbon dioxide of $0.8 \mathrm{~kg}$ for one day. One person would emit carbon dioxide of $292 \mathrm{~kg}$ each year, that is, carbon dioxide $0.292 \mathrm{t}$ each year, then 6.5 billion persons in the would emit carbon dioxide of 1.898 billion $t$. each year.

\subsubsection{The Carbon Dioxide Emitted by Smokers}

In china, now although in public field there are a lot of marks of no smoking, still there are a lot of people who are smoker. Smoking not only pollutes air environment, but also emitted large amount of $\mathrm{CO}_{2}$. The smokers are important sauce of emission of $\mathrm{CO}_{2}$.

\section{The Sink of Carbon Dioxide in the Atmosphere}

Would the carbon dioxide in the atmosphere increase continually? No, it would not. Because there is some carbon dioxide entering the atmosphere, and also there is some carbon dioxide going out.

Sink of $\mathrm{CO}_{2}$ in the atmosphere mainly has three: (1) Entering the Biosphere; (2) Entering the Ocean And. (3) Keeping in the atmosphere. In addition, certainly still there are outgoing ways, and that are the other sinks. For example, carbon dioxide absorbed by dissolving of carbonate, weathering of the rock, carbon dioxide absorbed by some building materials, and the some materials of purification function. [23]

\subsection{Entering the Biosphere}

The biosphere also is one of the most important barn of carbon in the natural world. In the atmosphere, there are about 2000 billion t. of carbon dioxide. Total carbon used by synthesis every year is about 200.0-300.0 billion $t$. in the natural world. [23]

\subsubsection{Photosynthesis of Green Plant}

In the natural world, the green plants, including plants on the land and the plankton in the sea water, or the ocean, all could absorb $\mathrm{CO}_{2}$ from the atmosphere. All green plants in the world each year could absorb 150 billion t of the carbon, that is, 550.1 billion t. of $\mathrm{CO}_{2}$. [23]

1) Photosynthesis of Green Plant on the Land

The forest and green grass land of one hectare (ha) could absorb $150 \mathrm{t}$ of $\mathrm{CO}_{2}$ and released $100 \mathrm{t}$ of oxygen.

Green plants on the land could absorb water and mineral substance from the soil, and absorb $\mathrm{CO}_{2}$ from the atmosphere, and by action of the solar light and chlorophyll, formed organic substance, and release oxygen: [23]

The photosynthesis of plants on the land:

By solar light, chlorophyll:

$$
\mathrm{xCO}_{2}+\mathrm{yH}_{2} \mathrm{O}=\mathrm{C}_{\mathrm{x}}\left(\mathrm{H}_{2} \mathrm{O}\right)_{\mathrm{y}}+\mathrm{xO}_{2}
$$


Here, $\mathrm{C}_{\mathrm{x}}\left(\mathrm{H}_{2} \mathrm{O}\right)_{y}$ represents organic substance; $\mathrm{O}_{2}$ represents oxygen.

2) Photosynthesis of the Green Plants in the Ocean

Plankton in the ocean is the Green Plants in the Ocean. The photosynthesis of the plankton in the ocean could absorb a lot of carbon dioxide, and release a lot of oxygen. Photosynthesis of the plankton in the ocean could express as follows: [23]

$$
\begin{gathered}
103 \mathrm{CO}_{2}+16 \mathrm{HNO}_{3}+\mathrm{H}_{3} \mathrm{PO}_{4}+122 \mathrm{H}_{2} \mathrm{O}= \\
\left(\mathrm{CH}_{2} \mathrm{O}\right)_{106}\left(\mathrm{NH}_{3}\right)_{16} \mathrm{H}_{3} \mathrm{PO}_{4}+138 \mathrm{O}_{2} \\
103 \mathrm{CO}_{2}+16 \mathrm{HNO}_{3}+\mathrm{H}_{3} \mathrm{PO}_{4}+122 \mathrm{H}_{2} \mathrm{O} \Leftrightarrow \\
\left(\mathrm{CH}_{2} \mathrm{O}\right)_{106}\left(\mathrm{NH}_{3}\right)_{16} \mathrm{H}_{3} \mathrm{PO}_{4}+138 \mathrm{O}_{2}
\end{gathered}
$$

So, the plankton in the Ocean is an important sink of the carbon dioxide from the atmosphere.

\subsubsection{Photosynthesis of Germs (Algae)}

Photosynthesis is not monopolistic specific property of green plants. Germs were living body most early that applied solar light to compose organic substances, and it is historical ancestors of higher plants in the natural world. Germs and algae could apply carbon dioxide by photosynthesis to compose organic substance, so they are an important sink of carbon dioxide from the atmosphere. Photosynthesis of germs (algae) could express as follows:

$\mathrm{NaHCO}_{3}$ and $\mathrm{H}_{2} \mathrm{~S}$ are harmful to plants, but these germs could used the energy produce by $\mathrm{H}_{2} \mathrm{~S}$ to assimilate carbon dioxide, to compose organic substance, that is [23]

$$
\begin{gathered}
\mathrm{CO}_{2}+2 \mathrm{H}_{2} \mathrm{~S}=\left(\mathrm{CH}_{2} \mathrm{O}\right)+2 \mathrm{~S}+\mathrm{H}_{2} \mathrm{O} \\
\mathrm{CO}_{2}+2 \mathrm{H}_{2} \mathrm{~S}=2\left(\mathrm{CH}_{2} \mathrm{O}\right)+\mathrm{H}_{2} \mathrm{SO}_{4}
\end{gathered}
$$

In addition, also there are some germs which could assimilate carbon dioxide by chemical energy to compose organic substance.

\subsection{Entering the Ocean}

The ocean, or the sea water, is one of the most important barn of carbon. There are about 130000 billion t., of carbon dioxide in the ocean. The area touched each other of the atmosphere sphere with water sphere is very large. Carbon dioxide from the atmosphere into the ocean is about 20.0 billion t., every year. [23]

The carbon dioxide in the atmosphere easily was dissolved in the sea water. Carbon dioxide dissolved in the sea water reacts with sea water, and forms carbon acid, or bicarbonate:

$$
\begin{aligned}
& \mathrm{CO}_{2}+\mathrm{H}_{2} \mathrm{O}=\mathrm{H}_{2} \mathrm{CO}_{3} \\
& \mathrm{CO}_{2}+\mathrm{NaOH}=\mathrm{NaHCO}_{3}
\end{aligned}
$$

The carbon dioxide absorbed by the sea water is about 20.0 billion each year. Because there is the seas water on the earth, concentration of carbon dioxide in the atmosphere would not increase with a unlimited way. If carbon dioxide in the atmosphere continually increased, and the part pressure also was getting higher and higher, then the carbon dioxide of the atmosphere would naturally be dissolved and enter the sea water.

\subsection{Keeping in the Atmosphere [23]}

Considering the balance of coming into and going out of carbon dioxide in the natural world, the carbon dioxide from the sea to the atmosphere is about 15.4 billion $t$ each year in the world, and carbon dioxide emitted to the atmosphere by combustion of fossil fuel is only about 10.0 billion, both together are 25.4 billion $\mathrm{t}$., and carbon dioxide absorbed by the sea only is 20.0 billion $t$., the difference of them is 5.4 billion t., which would be kept in the atmosphere, and so the carbon dioxide in the atmosphere would increase year by year. Some person would gladly say that increase of carbon dioxide in the atmosphere would lead to global warming! In fact, influence of increase of carbon dioxide in the atmosphere on the climate change is very very small. Everybody should not worry about this event!

\section{Carbon Dioxide Is Not Chief Culprit of Global Warming}

According to basic principle of classical physics and basic fact of climate change, we can prove that $\mathrm{CO}_{2}$ in the atmosphere is not most main cause led global warming, and also $\mathrm{CO}_{2}$ emitted by human activities is not the chief culprit led to global warming.

\subsection{Absorbency of Light Radiation of Carbon Dioxide Is Not Most High [24]}

According absorption of Solar radiation, it is evident that water vapor is most important greenhouse gas, and carbon dioxide is not most important greenhouse gas. The absorption of greenhouse gases for Solar radiation as a function of wavelength shows that the absorption peaks of $\mathrm{CO}_{2}$ mainly distribute between $2-25 \mu \mathrm{m}$, at which there are 3 absorption peaks, and the absorption peaks of water vapor distribute between $0.5-50 \mu \mathrm{m}$, at which there are 8 absorption peaks and especially between $20-50 \mu \mathrm{m}$ there is a continuous absorption band (Figure 1).

Evidently, absorption of water vapor for the solar radiation energy is much higher than that of the $\mathrm{CO}_{2}$. 


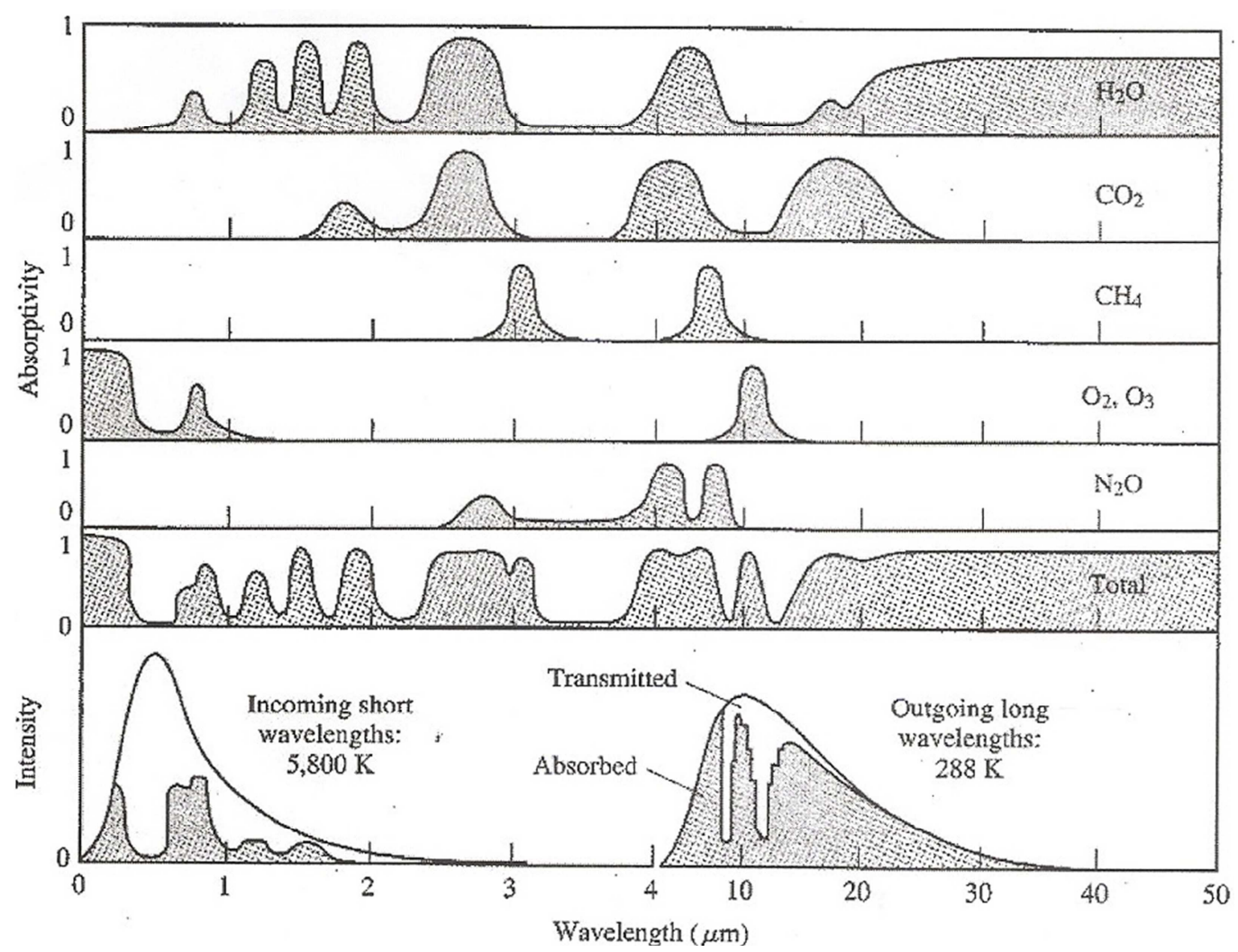

Source: Edward S. Rubin, et al., 2001, [24]

Figure 1. Absorption of greenhouse gases as a function of wavelength. Also shown are the intensity of incoming solar energy and outgoing terrestrial energy. The shaded area under each of these curves shows the amounts absorbed by greenhouse gases.

\subsection{Contribution of Carbon Dioxide to Greenhouse Effect Is Not the Largest [25]}

It can be calculated that contribution of carbon dioxide to greenhouse effect is not the largest. Average content of water vapor in the atmosphere on the Earth is about 10,000 ppm, and still the largest content of water vapor is about 400,000 ppm.

Now, content of $\mathrm{CO}_{2}$ in the atmosphere is about 385 ppm. It can be calculated that the contribution rate of water vapor to greenhouse effect should be:

$$
10000 /(1000+385) \times 100 \%=96.29 \%
$$

Whereas contribution rate of the carbon dioxide to greenhouse effect should be:

$$
385 /(110000+385) \times 100 \%=3.71 \%
$$

Here the calculated result stated that contribution of $\mathrm{CO}_{2}$ to the greenhouse effect is very small compared to that of water vapor.

\subsection{The Carbon Dioxide Emitted by Human Activities Is Very Small [25]}

According to the data from U. S. Energy Source Administration, now the total amount of carbon dioxide that the natural world and human activity emitted is about 793.1 billion tons, and amount of $\mathrm{CO}_{2}$ emitted by the human activity is about 23.1 billion tons. Based above data, It is calculated that

23.1 billion tons/ 793.0 billion tons $\mathrm{x} 100 \%=2.91 \%(14)$

Here the calculated result states that the $\mathrm{CO}_{2}$ emitted by the human activities, compared to the water vapor in the atmosphere, is very, very small, and so which cannot result in evident change of global climate.

\subsection{Relation of Both Carbon Dioxide and Change of Air Temperature Is Not Linear}

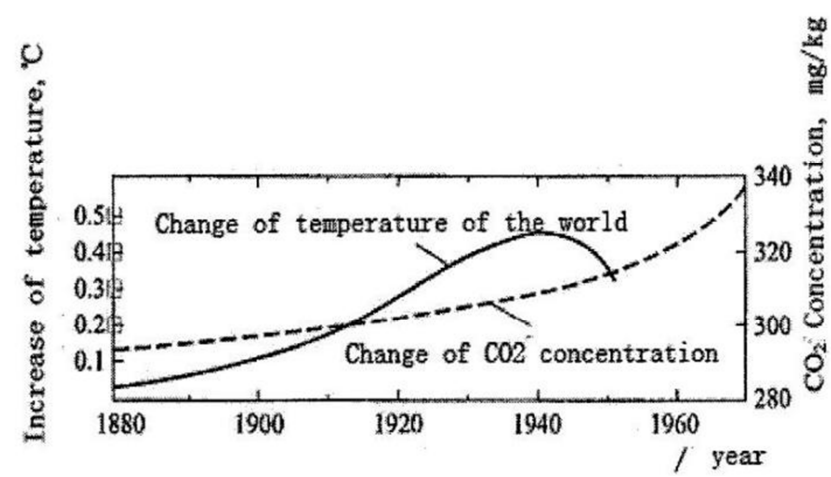

Figure 2. Change of $\mathrm{CO}_{2}$ concentration and change of air temperature of the world. Source: Guo Yuanzhen, et al. $\mathrm{CO}_{2}$ and Climate, 2012. [23] p. 81.

The data of the weather observation stated that in the last more than 100 years, the $1890-1924$ is low temperature period 
and the 1925-1946 is high temperature period, and also the 1947-1976 is low temperature period and also still the 1977-2000 is high temperature period, and however, in these years, $\mathrm{CO}_{2}$ emitted by human activities has been increasing year by year. [23] p. 107

It is stated that change of the Atmospheric temperature is not corresponding to change of the concentration of carbon dioxide.

\subsection{Change of Air Temperature only Is Relative to Kinetic Energy of Air Molecules}

From Maxwell's speed distribution law, it can be known that air molecules for certain temperature that locate at the balance state have a speed distribution. From the speed distribution law, the following relation cold be led to

$$
\sqrt{\overline{v^{2}}}=\sqrt{\frac{3 k T}{m}}
$$

where, $k$ - Boltzmann constant; $m-$ quality of the molecule, and by which next relation could be led to:

$$
\frac{1}{2} m \overline{v^{2}}=\frac{3}{2} k T
$$

If $\bar{\omega}$ is used to represent average kinetic energy of the molecules then it could be rewritten to:

$$
\bar{\omega}=\frac{3}{2} k T
$$

From here it can be seen that average kinetic energy of the gas molecules, $\bar{\omega}$, is direct proportional to gas temperature, $T$. It should be noticed that proportional coefficient $\frac{3}{2} k$, only a universal constant, which is not relative to kind of molecules. It is stated that gas temperature represents intense degree of movement of molecules. Thus, it can be known that the atmospheric temperature is relative to movements of all the air molecules, and is not monopolistic of the greenhouse gases.

\section{Conclusion}

1) Natural factors are the main cause led the climate change, and the influence of anthropological factors on climate change is very and very small.

2) Emission of Carbon Dioxide is not main cause led to climate warming, and and also Carbon Dioxide emitted by human activities was not a chief culprit led to global warming.

3) Rise of average air temperature of the earth surface is resulted from increase of heat radiation of the sun and the earth.

4) Largely decreasing emission of Carbon Dioxide could not control global warming, and also not prevent happening of climate disaster.
5) Largely decreasing emission of carbon dioxide, would exhaust the people power and drain the treasury of the Governments, and would impact on normal development of the National economy.

6) We would like to suggest that the Governments all over the world do not easily believe so called "global warming", and also do not attend and support the international activities led by IPCC to advocate and to trumpet so called "global climate warming".

\section{Acknowledgements}

The author is enormously grateful to Prof. W. X Wang the academician of the Engineering Academy of China, and Prof. Zhenhai Ren, the academician of the Engineering Academy of China, and Prof. Fuqing Su, Agricultural University of China, for their offering many help and suggestions while the author was writing the paper.

\section{References}

[1] IPCC, 1990. Climate change: first Scientific Assessment Report. Editors:J. T. Houghton, O. J. Jenkings, and J. J. Ephraums, Intergovernmental Panel on Climate Change, UH: Cambridge University Press.

[2] IPCC, 1992. Climate change: first Scientific Assessment Report Complement. Editors:J. T. Houghton, O. J. Jenkings, and J. J. Ephraums, Intergovernmental Panel on Climate Change, UH: Cambridge University Press.

[3] IPCC, 1996a. Climate change 1995: Second Scientific Assessment Report. Editors:J. T. Houghton et al, Intergovernmental Panel on Climate Change, UH: Cambridge University Press.

[4] IPCC, 2001. Climate change: Third Scientific Assessment Report. Intergovernmental Panel on Climate Change, UH: Cambridge University Press.

[5] IPCC, 2007. Climate change: Fourth Scientific Assessment Report. Intergovernmental Panel on Climate Change, UH: Cambridge University Press.

[6] IPCC, 2013, 2014. Climate change: Fifth Scientific Assessment Report. Intergovernmental Panel on Climate Change, UH: Cambridge University Press.

[7] Qin, Dahe, Human Activities Accelerate Global Warming: http://it.sohu.com/20070908/n252033491.shtml (Chinese)

[8] Lin, Erda, Jinlong Xu, Shiming Ma. Global Warming Leads to More and More Poor: http://green.sohu.com/20090617/n264584105.shtml (Chinese)

[9] Ding, Yihui. Worry and Think of Global Warming: http://blog.sina.com.cn/s/blog_1304649a30102wypo.html (Chinese)

[10] Yang, Xinxing. Climate Change on the Earth and Its Main Causes Frontier Science, 2017, 11(3): 10-23. (in Chinese)

[11] Yang, Xinxing. Atmospheric Greenhouse Effect Is a Pseudo Proposition, Frontier Science, 2017, 11 (1): 22-31. (in Chinese) 
[12] Yang, Xinxing. Carnon Dioxide Is not the Chief Culprit, of Climate Change, Frontier Science, 2016, 10 (1): 29-39. (in Chinese)

[13] Singer, S. Fred, Dennis T. Ivoly. Climate Change: an Unstopable Trend of Nature, Frontier Science., 2016, 10 (2): 33-43. (in Chinese)

[14] Yang, Xinxing. Low Carbon Economy Is Short of Theoretical Basis and Fact Evidence, Frontier Science, 2011, 5 (3): 16-21. (in Chinese)

[15] Liu Yu, Cao Jiang, Zhu Shenbao. Challenging Climate Change: Carbon Dioxide Capture and Storage.. Frontier Science, 2010, 4 (1): 40-51. (in Chinese)

[16] Yang, Xinxing. Climate Warming Is a Fraud. Frontier Science, 2010, 4 (4): 31-34. (in Chinese)

[17] Zhang, Hao. Interviewing Prof. Abodusaef, a scientist of Astronomy of Russia. News Paper of Science and Technique, 01/02, 2010. ( in Chinese)

[18] Wanshanmoude. Carbon Dioxide Is not the Culprit of Global Warming, Selection, 2008, (2). [Japanese]

[19] Singer, S. Fred, Dennis T. Ivoly. Unstoppable Global Warming: Every 1500 Years. Roman \& Littlefield Publishing Group, 2007. (in Chinese)

[20] Wang, Mingxing. Global Climate Change: How much We Really Know? 01/18, 1998, (3). News Paper of Chinese Science.

[21] Ding, Zhongli. Climate Change and the Game of Benefit in the Back Side. http://www.news365.com.cn/bsjhcdjy/201104/t20110410 300 6018.htm. 2011-04-10 (in Chinese)
[22] Jiang, Xiaoyuan. Science and Politics: the Truce Sense of "Global Warming". Science and Society, 2013: 3 (2): 38-44, (in Chinese).

[23] Guo, Yuanzhen,, Mijun Peng. Carbon Dioxide and Climate. Chemical Industry Publishing House, Beijing, 2012. (in Chinese).

[24] Edward S. Rubin and Cliff I. Davidson. Introduction to Engineering \& the Environment. McGraw - Hill Companies, Inc., 2001, pp. 482-483.

[25] Today Reviewer. A Simple Lie: Carbon Dioxide Made by Human Made Global Warming. http://biaochiwang.com/blog/archives/534.( in Chinese).

\section{Biography}

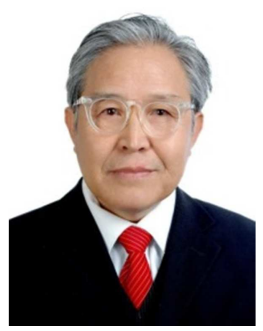

Xinxing Yang is an Emeritus Professor of Environmental Science at Chinese research Academy of Environmental sciences. His research interests are atmospheric pollution and climate change. From 1965 to 1985 , he served, as an assistant research member, in the Chinese Academy of Agricultural sciences. From 1985 - 2000, he served as a vicedirector of the Atmospheric Survey Laboratory. Mr. Yang is a member of Chines Society of Environmental Science. His honors and awards include the award from the environmental Protection Department, China, the qualification certificate of environmental assessment, and the commemorative badge for 30 years of environmental detection works. 